\title{
LOS APODOS: INDIVIDUALIZADORES CONCEPTUADOS
}

\author{
Nicknames: Conceptual individualizers
}

\author{
Bruno Cárdenas Maragaño*
}

Resumen

El artículo examina, primeramente desde una perspectiva diacrónica y luego sincrónica, el surgimiento y evolución de los apodos, un particular tipo de nombres por medio de los cuales se pretende comprobar que, no obstante ser un ejercicio verbalizado de comunidades marginales, abarca todos los niveles socioculturales interviniendo variados recursos gramaticales, mediante los cuales una persona es identificada y definida en función de alguna circunstancia que lo vincula. Seguidamente se analizan las características, referentes, recursos de composición y sentido, a partir de un corpus seleccionado entre distintos segmentos culturales y, luego en un corpus seleccionado desde centros penitenciarios del centro sur de Chile, en donde el ingenio, la comicidad, el sarcasmo y secretismo contenido - motivo por el cual requieren de explicación— están en la base de las creaciones apódicas.

Palabras clave: Apodos en diacronía y sincronía. Identificadores que definen. Apodos en segmentos socioculturales. Hipersemias. Ingenio. Eponimia.

\section{Abstract}

This article first examines, from a diachronic and synchronic perspective, the rise and evolution of nicknames, a specific type of names through which it is intended to verify that, despite being a verbalized activity of marginal communities, it includes all the sociocultural levels by intervening various grammatical resources from which a person is identified and defined based on a certain circumstance $\mathrm{s} / \mathrm{he}$ is linked to. The characteristics, referents, resources of composition and sense are analyzed based on a corpus selected from different cultural segments and, then on a corpus selected from penitentiaries of the central south in Chile, where ingenuity, comicality, sarcasm and restrained secrecy - the reason why they require further explanation - form the basis of the creation of nicknames.

Key words: Nicknames in diachrony and synchrony, Identifiers that define, Nicknames in sociocultural segments. Hypermimia. Ingenuity. Eponymy.

\section{ANTECEDENTES}

El lenguaje es una realidad mediante el que expresamos y manifestamos simbólicamente pensamientos, ideas y emociones, como resultado de una actividad humana constante. Existe consenso en admitir que el lenguaje es una facultad de dos caras, es un arma de dos filos; en un caso puede ser instrumento para la creatividad, la búsqueda del saber y la verdad para penetrar en las honduras del alma y, por otro, un medio para provocar exactamente lo contrario, es decir, un freno a la creatividad y 
un medio para la manipulación de las conciencias y fomentar el ansia de poder, atrayendo a pícaros, truhanes, demagogos; aunque, convengamos, la tendencia es a considerar el lenguaje como una actividad tan seria que en su realización primigenia, como lengua oral, se le ha dotado de un valor sagrado.

Lo primero fue la voz como lenguaje vocalizado, luego la palabra, acaso por lo mismo es representación de la presencia física, pues es timbre, amplitud, altura y registro, es decir, la voz considerada como primera forma de identidad personal.

En la gran Nada primordial irrumpe la palabra en la boca de los dioses. En el Popol Vuh leemos que no había nada dotado de existencia, que estuviera en pie: sólo el mar y el cielo en toda su extensión, ambos vacío y en reposo y entonces llegó la palabra: Tepeu y Gucumatz hablaron en la oscuridad. O sea, la palabra no esperó que el hombre existiera... Hágase la luz, dijo el Dios del Génesis, y por cierto hubo luz. Después la palabra hizo el día y la noche. Entre la palabra pronunciada y el acto no había distancia alguna, pues el poder hacer por medio de la palabra es un atributo esencial de los dioses (Colombres, 4).

Con todo, y más allá de las dimensiones sagradas y excelsas, el lenguaje como agente mediador ofrece recursos mediante los cuales opinamos, discutimos, proponemos, nombramos y cumplimos con la exigencia legal de dotar de nombre en un Registro Civil Nacional de Identificación, mediante el cual se individualiza a una persona tanto por su nombre propio, o de pila, como por su nombre patronímico de familia y que una vez inscrito da lugar a lo que se denomina partida de nacimiento. Ambos constituyen los componentes individualizantes básicos de lo que la ley civil considera como atributo de personalidad en la persona natural. En cambio, desde el punto de vista de la norma legal, el sobrenombre o el apodo que, eventualmente se pueda emplear para denominar a una persona, carece de valor jurídico.

El estudio de los apodos forma parte de la antroponimia, que es la disciplina de la onomástica que relaciona y estudia los nombres de las personas, particularmente los nombres propios, siendo materia de estudio perteneciente al ámbito de las expresiones de tratamiento, del mismo modo como pueden ser las formas pronominales o, simplemente, nominales como es el caso del apodo, como sucede con el nombre propio, el apellido, los hipocorísticos, entre otros. Al revisar distintos trabajos bibliográficos sobre el tema, que para el caso de Chile son más bien escasos, se tiende a aludir al apodo en equivalencia semántica con los motes, los alias o los sobrenombres - aunque no todo sobrenombre es un apodo-, que se asignan a una persona por una cualidad o condición suya, como lo refiere el DRAE.

El nombre apodo y la acción 'apodar', $<$ del lt. apputare $<$ lt. putare significa desde esta dimensión etimológica, podar, poner en limpio, calcular, evaluar (Corominas, 238). Más tarde, a partir del primer tercio del siglo XIII, significará comparar, lo que será un dato interesante, toda vez que contendrá el aspecto de base sustentador desde el que se crea el apodo, es decir, que existe del mismo modo como 
se construye la metáfora, una figura recurrente en este tipo de sobrenombres, esto es, un plano real y otro imaginario ligándose ambos a partir de una base de comparación.

Indistintamente se suele emplear el apodo o mote como términos análogos. El diccionario de M. Moliner define el apodo como el sobrenombre aplicado a veces a una persona, entre gente ordinaria, y muy frecuentemente en los pueblos donde se transmite de padres a hijos. A su vez, define mote como el sobrenombre, generalmente alusivo a alguna cualidad, semejanza de la persona a quien se aplica, por el que se conoce a esa persona (Moliner, 462).

Por su parte, el DRAE define mote (del cat. o del subgrupo galoibérico occitano 'mot' y este probablemente del b. lt. 'multum'), como una sentencia breve que incluye un secreto o misterio que necesita explicación. //5. Sobrenombre que se da a una persona por una cualidad o condición suya, apodo. (DRAE, 932)

En las definiciones se precisan los aspectos o "requisitos" mediante los cuales un término alcanza el estatuto de apodo o sobrenombre, entre los cuales podemos mencionar una potente función apelativa y diferenciadora; que tenga vigencia temporal; que se construya en buena medida desde un proceso permanente de metaforización y desemantización. Los apodos son construcciones en las que se canalizan componentes de diversa motivación, por ejemplo, en unos casos se involucran afectos, o bien, existen como dimensión satírica, peyorativa, por medio de las cuales se formula un denominador que caracteriza y caricaturiza de manera particular a un individuo conocido.

Los apodos son, entonces, construcciones lingüísticas poseedoras de identidad y significado de focalización cultural, diferenciadores personales para bien o para mal. Constituyen una forma de identidad adquirida y no se transmiten del modo como los apellidos, no es la familia la que decide o determina el apodo, a diferencia del nombre civil que es adscrito.

Sumariamente, el apodo:

a) Redesigna o, al decir del DRAE, repone, recoloca un nombre.

b) Es una resignificación del nombre propio desde una dimensión figurada, expresiva/emotiva. Desde una dimensión semiótica, como veremos más adelante, puede ser corporal, actitudinal, moral, etcétera, mediante imágenes retóricas, como las metáforas, circunloquios, polisemias, sinécdoques, hipérboles, hipersemias y antisemias, entre otras.

c) Además de una resignificación, los apodos se construyen como identidad paralela surgida a partir de la adscripción de un nombre que es distinto del propio, ya sea por algún rasgo, o una característica, incluso por una acción fortuita, que resulta ser cualificante del sujeto portador.

d) Al acontecer lo anterior, sucede una transferencia de significado mediante la metáfora, en tal caso existen en la base del apodo dos planos: el real y el imaginario de manera comparativa, es decir, sin oponerse. 
e) Existe en el apodo una intencionalidad humorística, pícara, mordaz, peyorativa, laudatoria o atributiva de cualidad altisonante.

f) Puede ser considerado en ciertos casos un acto de juzgamiento.

g) Siempre va precedido de un determinante "El", "La", que es potenciador del nombre, pero, al mismo tiempo el artículo cosifica, cuan más, cuan menos, en equivalencia a un objeto o cosa, por ejemplo, "la bisagra", "el termómetro", "el cónsul”, etcétera.

\section{LOS APODOS EN SU DIACRONÍA}

Los apodos son construcciones surgidas en un momento en el que los nombres de pila fueron absolutamente insuficientes, en términos que existía una desproporción entre el número creciente de personas y un mínimo de repertorio en el santoral, a ello había que agregar que aún no existían los apellidos; de manera que el problema no era menor, toda vez que había una exigencia y demanda por identificar entre personas, ya que en una misma localización existían individuos con el mismo nombre, lo que, ciertamente, generaba gran confusión y ambigüedad. De tal manera que era menester recurrir a un "denominante" que permitiera, por lo pronto, resolver el problema y una de las prácticas fue el denominar atendiendo a una característica o rasgo particular del individuo por filiación, siendo este último el de mayor recurrencia, y empleándose el mecanismo gramatical de la sufijación del patronímico en "ez", por ejemplo, González, hijo de Gonzalo; Sánchez, hijo de Sancho; Martínez, hijo de Martín. Este nombre calificativo y por su duplicidad se conoció como "sobrenombre", dando lugar al "apellido", es decir, el "apelativo", que es lo que etimológicamente significa.

Respecto del nombre de "pila" es interesante precisar este proceder nominal, porque el nombre le era impuesto a la persona al pie de la pila o fuente bautismal, y que es el único nombre que en sentido estricto es propio, toda vez que el apellido es común al seno del colectivo familiar. "Los apellidos empiezan a imponerse en la aristocracia, y poco a poco van afectando a las capas socialmente más bajas, hasta que el registro civil iguala a todos en el 'derecho' a tener apellidos. Pero el caso es que la costumbre ha hecho pervivir los apodos [principalmente] en zonas rurales y en las comunidades pequeñas. Los apodos siguen identificando a las personas mejor que los apellidos dentro de algunos grupos sociales, como ocurre, por ejemplo, entre [los futbolistas, los boxeadores] los gitanos, los cantes, los artistas, los toreros" (Trapero, 352).

Los ciudadanos de la República Romana, condición alcanzada por los aristócratas, que eran los hombres libres, poseían tres nombres o tria nomina como se denominaba (Faure, Diccionario de nombres propios): el praenomen, el nomen y el cognomen. El praenomen correspondía al nombre asignado en la ceremonia bautismal, de allí que era y es llamado 'nombre de pila', por ocurrir en torno a la pila, suceso que acontecía al octavo día de nacimiento en el caso de los niños y al noveno en el caso de las niñas, antes de los ocho días era llamado 'pupus', que significaba 'muchachito'. Ese 
día se llamaba 'lustricus dies' - 'lustral', día de la purificación, o día del bautismoHabitualmente el primogénito portaba igual nombre que el del padre.

El 'nomen' correspondía al nombre hereditario de familia, es decir, del gens al que se pertenecía y era el más recursivo, sobre todo en los casos cuando el hombre carecía de un tercer nombre, por razones de carencia de rango aristocrático. Por su parte, a las niñas se les otorgaba solamente el nomen.

El cognomen era el tercer nombre - después del praenomen o del nomen-y correspondía al sobrenombre individual. Ejemplos: Marcus Tulio Ciceron, cognomen Cicero lt. cicer,-eris = garbanzo y por extensión 'verruga' rasgo físico en el rostro de Marcus Tulio. El cognomen también daba cuenta del orden de nacimiento del individuo al interior del grupo familiar: Prima, Secunda, Tertia, etcétera.

Entre los siglos X y XIII se produce lo que se conoce como "revolución antroponímica" (Suárez, 61), en términos de generalizar la designación de las personas con dos elementos, es decir, al nombre propio único (el nomen) se adiciona un cognomen o sobrenombre que corresponderá, a partir del siglo XI, al apellido familiar; esto cobrará mucha importancia, pues la evolución en la manera de designar a los individuos estará dando cuenta de cambios en las estructuras ideológicas y socioeconómicas. Para el caso de la mujer, los dos nombres será un asunto más tardío, pues al estar confinadas a los quehaceres del hogar, no tenían emprendimientos externos ni participación en actos jurídicos: “...la designación complementaria que más va a utilizarse es el cognomentum, un nombre o, en cierto modo, un apodo que viene a complementar el nomen baptismi...", lo que otorga una identificación más definida.

En el período romano las hijas, cuando correspondían a un núcleo de familia en términos de adquirir el carácter de ciudadana, eran portadoras del nombre del clan — del padre - en el que habían nacido, con la adaptación del morfema de género. Por ejemplo: de Cornelius = Cornelia. En el caso de existir más de una hija, se empleaba el adjetivo maior o minor, o bien los ordinales, prima, secunda, tertia, etcétera.

El cognomentum, s.m., era el renombre que adquiría una persona, por ejemplo, Alfonso el Sabio; Alejandro Magno, es decir, se toman cualidades, reconocimientos de un individuo, o bien, sencillamente se incorporaba otro nombre como una cuestión complementaria al nombre de pila que había caído en limitaciones, por consiguiente, se hizo necesario el uso de un segundo nombre. En sentido estricto, el cognomen, del plural cognomina, correspondía a los "Nombres hereditarios de las familias romanas, más o menos equivalentes a nuestros apellidos. En origen eran sobrenombres personales, pero a principios del siglo I a.C. se hicieron hereditarios para distinguir las diferentes ramas de un mismo tronco gentilicio" (Faure, Apellidos españoles, XXI).

Los cognominos tuvieron, en principio, procedencia masculina proveniente del nombre paterno, entre otras razones porque era ante los demás la cabeza visible del grupo familiar, además, era el portador de cualquier bien patrimonial. Posteriormente, en la segunda mitad del siglo XII, se incorporaron sobrenombres atendiendo a otros 
referentes, por ejemplo, de lugar (apodos toponímicos) y de actividad, como Alvar Otero, Gadea Herrero, es decir, se comenzó a ampliar, dinamizar y complejizar el sistema antroponímico.

En el caso del español, el sistema antroponímico en cuanto a su proveniencia romance tiene como antecedente, entonces, el correspondiente latino, el que presentaba complejidades, principalmente a nivel del estrato social más pudiente, en el que se utilizaban hasta cuatro nombres, en la idea que la identificación fuera absoluta, y de tal manera que no quedaran dudas para confusión con algún otro individuo de otra condición social inferior, como los plebeyos que tenían solo un nombre o apodo; por consiguiente, existía el praenomen, equivalente a lo que sería el nombre de pila; el nomen gentilicium correspondiente al nombre de la familia (tribu) a la que pertenecía; el cognomen, equivalente al apodo relacionado con algún rasgo distintivo del individuo, en consecuencia, este último nombre no siempre estaba incorporado, “.... veces se añadía el agnomen, que era como un apodo alusivo a una circunstancia personal del individuo" (Faure, Apellidos españoles, XXXIII).

El proceso político de romanización y, luego, la cristianización europea, en especial para el caso de España, dio lugar a un potente sistema antroponímico de nombres de dichas procedencias, por tal motivo comienzan a imponerse $y$ popularizarse nombres de personajes bíblicos y de la santería cristiana: "La nueva onomástica cristiana simplificó el sistema romano, y es probable que se volviera al uso del nombre único: el nombre de bautismo. La cristianización favoreció la popularización de nombres hebreos y griegos citados en el Antiguo Testamento, en los Evangelios o en los Hechos de los Apóstoles, como David, Salomón, José, María, Juan, Mateo, Marcos, Lucas, Pedro, Alejandro, etc." (Faure, Apellidos españoles, XXXIV). Más tarde, y en consonancia con la dinámica de los procesos históricos, en la península ibérica se produjeron modificaciones en el sistema onomástico español, entre otras razones por las invasiones como la musulmana en el año 711, luego de lo cual España se constituyó en un emirato generándose una prolongada convivencia, que tuvo sus resultados en el campo de la civilización, ya sea en el desarrollo de la agricultura, la industria y la cultura. En este último aspecto, a nivel del idioma, hubo un influjo de aportes notables a nivel del superestrato lingüístico que se reflejó, entre otros aspectos, en los nombres propios siguiendo su proceso de semantización, por ejemplo, 'Fátima': fatama=destetar, mujer joven, virgen; Omar: umar $=$ el próspero, el constructor (Faure, Nombres propios, 640); Almudena: al-mudayyina, diminutivo de madina $=$ ciudad (56). Posteriormente invasiones vividas como las germánicas aportarán en el mismo ámbito nombres, p.e.: Rodrigo: hrod='gloria, fama' y -ric, 'poderoso' (717); Fernando: frid='paz', y -nand='audaz, atrevido' (351), Bernardo: berin-/bern, derivado de ber='oso', y -hard='duro, fuerte' (167), Ricardo: ric=poderoso', y -hard='duro, fuerte' (712).

Durante el siglo XVI, como lo reporta M. Chevalier (61) el apodo o mote era entendido como un acto de ingenio mediante el cual se relevaba o censuraba a un sujeto, 
es decir, constituía un pasatiempo que por tratarse de un entretenimento cortesano debía responder a un nivel propio de la condición, en tal sentido debía mantener un nivel que le permitiera diferenciarse del bufón; no incluir a los poderosos en este "divertimento"; excluir de las chanzas a los criminales y marginados; evitar referirse a defectos físicos y vulgares. Las estrategias recursivas de creación de apodos utilizadas fueron las comparaciones ingeniosas, y degradantes al mismo tiempo, hipérboles, juegos de palabras por disociación, equívocos y paralelismos, entre otros.

Más tarde, los apodos cumplieron la función de apellidos hereditarios para complementar el nombre de nacimiento, como sucedió también con la procedencia, la profesión o la actividad antes referida. Cada vez se incrementó el número de personas en contraposición al número limitado de nombres, cuestión que forzó la incorporación del segundo nombre. En una mirada actual, en Chile el repertorio de nombres propios fluctúa entre 10.000 y 11.000 , considerando aquellos de procedencia extranjera como Jonathan, Byron o Bairon, Thiare, Jennifer, Christofer, Brad, Jimmy, etcétera. De cualquier manera, y debido a que el número de habitantes es creciente, se hace necesario un segundo nombre, así como en la Edad Media el solo nombre de pila hizo necesario el apellido.

En el contexto de las limitaciones del repertorio de nombres que presentaba la designación de nombres de pila, los apodos cumplieron un rol importante, derivados de oficios, cargos o procedencia toponímica, por ejemplo, Pedro del Valle; Iñigo de la Vega; Leonor Villanueva; Nuño del Río, es decir, se tiene como referente una variedad de aspectos toponímicos como montes, riachuelos; en otros casos el lugar de habitación como 'Casagrande' o de una población, tal el caso de 'Villanueva', o aquellos otros de referencia forestal: Robles, Del Pino, Olmos, Castaño, Laurel, o bien, a nivel de oficios: Barbero, Herrero, Sastre, Carpintero, Cantero, Molinero, Escudero, entre otros.

Los apodos son, entonces, apelativos que siempre han estado presentes, aunque con mayor recurrencia en ambientes de cercanías y en grupos delimitados, tal es el caso de las zonas rurales, las villas, en la oficina y, en general, donde transcurre la cotidianeidad, "de lo cual resultarán apodos cariñosos, graciosos, ofensivos, crueles, malintencionados, en cuyo caso suele darse un rasgo que no es infrecuente como es una cierta complicidad" (Ramírez, 261). Lo interesante es constatar que el dinamismo histórico y de creación lingüística de la lengua es aplicable a los distintos niveles, difundiéndose de preferencia por la lengua común, pues allí los apodos cumplen funciones supletorias de identificación de origen; es más, los primeros nombres propios se constituyeron como apelativos de identificación, que daban cuenta de alguna característica, cualidad, valores, habilidades o defectos. Si se atiende a la etimología de los nombres, en muchos casos su referente primario es, precisamente, un rasgo apelativo que en su transitividad se resemantiza como heredero de un apodo, quedando constituido como antropónimo. Tenemos por ejemplo, 'Albino' adj. 'blanco' nombre que debió ser en su origen un apodo aplicado 
a la persona de cabello cano o de piel clara; la misma explicación es válida para el nombre propio 'Cándido', es decir, 'blanco', aunque luego tomó el sentido de 'sincero', 'transparente', de lo cual derivó en 'Candidato', que 'brilla por su blancura".

Es efectivo que el apodo es una creación lingüística motivada que responde a alguna característica del individuo, que resalta algo relevante y lo hace reconocible inductiva o deductivamente; es decir, no es un signo inmotivado, sino que responde a una causa. Esta es una característica que lo diferencia en gran medida del nombre propio, además de carácter no oficial [aunque el sujeto portador pueda, luego, oficializarlo, p.e. José, reemplazado en el Registro Civil de nombre por 'Pepe', Pepe Auth] (Ramírez, 264).

Sin embargo, estos nombres observados en el tiempo se independizan de su origen motivacional, por tal motivo son percibidos como nombres propios genéricos para quien lo porta, lo que no quiere decir, en ciertos casos, que exista un cierto funcionamiento denominativo de significado explícito, p.e., Aurora, Estrella, Estela, Verónica, Desiderio, etcétera.

En general, el uso de apodos da cuenta (de forma denotativa y connotativa) de una pluralidad de interrelaciones - mapa conceptual—, de una gran riqueza lingüística, sociológica o humanista; el mejor ejemplo es la gran cantidad de posibilidades y tipologías como las de Díez; de Moreu-Rey (citado por Ramírez). En general, el apodo cumple una interesante función descriptiva de las personas, en términos de describir, dibujar representativamente mediante el lenguaje, en algunos casos con un alto significado agresivo o lo contrario, muy próximo al insulto, la ofensa y la descalificación degradante; en otros, de modo eufemístico, para dar cuenta de conductas sociales y modos de convivencia.

\section{DEL APODO AL APELLIDO}

Desde un punto de vista etimológico, no todos los apellidos se formaron a partir de la filiación, p.e., Álvarez, Fernández, Hernández, González o Martínez, hubo muchos otros nombres que en el tiempo se estatuyeron como apellidos motivados en sus orígenes, atendiendo a algunos rasgos o antecedentes de referencia de mucha elocuencia y fácilmente identificables, como aquellos que se ejemplifican con apodos referidos a aspectos físicos, fitonímicos, zoonímicos o características morales, p.e., Alegre, Mohíno, Gallardo, Cazurro, etcétera; por lazos de parentesco, estado civil o edad, p.e., Sobrino, Casado, Nieto, etcétera, en otros casos respondiendo a alguna circunstancia anecdótica de la vida de la persona, p.e., Pescador, Piedra, etcétera, que resultaron ser más caracterizadores e identificadores que los nombres de pila. En general, los campos semánticos referenciales más propicios, significativos y esenciales de la vida cotidiana fueron nombres comunes, por consiguiente, no es necesario explicar el origen de la palabra, más bien interesa el motivo o rasgo en este 
caso, que convierte el nombre en apellido como su complemento, proviniendo de un apodo, entre los que podemos mencionar los siguientes cognominadores:

a) Rasgos físicos: Rubio, Moreno, Pardo, Negrón, Blanco, Crespo, Cano, Calvo, Cabezón, Chamorro, Pequeño, Chico, Delgado, Gordillo, etcétera.

b) Rasgos fitonímicos: Flores, Manzano(ares), Naranjo, Pino, Oliva, Lechuga, Alcachofa, Espárrago, Castaño, Cerezo, Tomillo, Prado, Romaguera, Romero, etcétera.

c) Rasgos zoonímicos: Conejo, Vaca, Toro, León, Becerra, Águila, Gavilán, Mosca, Gallo, Gato, Novillo, Merino, Halcón, Raposo, Vicuña, Cordero, Sierpe, etcétera.

d) Referentes toponímicos: De la Peña, Del Valle, De la Fuente, Del Pedregal, Del Campo, Del Río, Del Pino, De la Vega, etcétera.

e) Referentes hidronímicos: Lagos, Ríos, Laguna, Fuentes.

f) Rasgos emocionales, morales u otros: Alegre, Bueno, Morales, Valiente, Hermoso, Gallardo, Cortés, Noble, Bravo.

g) Desde un vínculo parental, estado civil o edad: Sobrino, Casado, Mayor, Nieto, Viuda, Ahijado.

h) Cargos, oficios o títulos: "Los motivos para su formación pudieron ser varios; en su mayor parte, estos linajes se formaron a partir de apodos relativos a muy diversas circunstancias: personas muy beatas, solitarias, o que habían abandonado el hábito religioso, o habían sido monaguillos, o servían en un monasterio,... p.e., abad, obispo, capellán, sacristán" (Faure, Apellidos españoles, XXV)

i) De variada referencia, tanto física, comportamiento, o deformación: Botín, Braga, Redondo, Verdugo, Casillas, Cuevas, Seisdedos, Culón, Espantoso, Sierra, Trapero, Putero, Barbero, etcétera.

\section{EL APODO IDENTIFICADOR QUE DEFINE}

Como todo proceso lingüístico sujeto a la diacronía, existen nombres de personas que sufren un desgaste o envejecimiento en su uso por exceso de recurrencia, dicha masificación ha significado una ambigüedad que si bien permite nominar, no significa necesariamente identificar; en tal caso, aunque ciertamente acontece a nivel informal, el apodo agrega alguna característica complementaria en una suerte de antroponimia supletoria déctica que asigna un significado propio y único del sujeto de identificación, por ello es más recurrente en los espacios de comunidades más reducidas en las que se moviliza, p.e. en el medio laboral, el del vecindario o el recreacional. En todos los casos, el apodo responde a una dinámica distinta respecto del estatuto del nombre propio, toda vez que se trata de un signo cargado de conceptualización y no un mero referente individualizador: "El apodo sería producto de una necesidad de nombrar a las cosas o personas con un nombre más adecuado del que tienen. Estaría en la manera en que un pueblo denomina al de 
al lado... en la manera en que llaman los de un equipo de fútbol a los de otro..." (García Jordán, 211)

Se trata de un signo que se relaciona con el individuo en tanto personaje actuante de una situación, algunas veces característicamente caricaturizada, pero no evidenciada para los demás; sin embargo, la circulación y popularización del apodo conlleva el motivo de la historia que lo motivó, y allí, en el circuito de los usos quedará expuesto a su vigencia o desaparición, dependerá de lo certero, acertado y adecuado.

No parecen existir dudas respecto de que en el apodo opera una efectiva correspondencia entre el nombre y lo nombrado:

La adecuación perfecta entre signo y referente se da en el mote o epónimo, en el que se reconoce una atribución integrada en el nombre. Unas veces señala una cualidad intrínseca del nombrado, en otras ocasiones corresponde a una atribución extrínseca, por contigüidad o semejanza. El mote representa el caso límite de motivo transparente, concuerda o contrasta con su portador (Iglesias, 299).

Los apodos son signos en los que se manifiesta una intensa motivación que hace que el nombre defina; el individuo pasa a formar parte metaforizada del nombre, ya sea por un rasgo interno o externo, de tal manera que al identificar y definir se revela en pleno la calidad del portador.

El apodo responde a la necesidad de que cada quien tenga una identidad nominal que lo distinga, y le dé vida, en cuanto se trata de un sujeto que se recrea mediante la palabra que lo designa, es decir, el apodo funciona no solo como nombrador, sino también como animador, sin excepción de nivel sociocultural, desde los hinchas futboleros hasta personajes históricos. Ejemplos: "Las Madres"; "Los Zorros del Desierto", apodos genéricos aplicables a los partidarios de los clubes Universidad de Chile y Cobreloa, respectivamente. Entre los futbolistas: "El Cabez'e Muela" Tapia; "El Celia Punk" Vidal; "El Cholga" Díaz; "El Pitbull" Medel, todos ellos personajes del fútbol chileno. En los empresarios chilenos: "El Luqui" Luksic; "El Choclo" Délano; "El Manano" Larraín; "El Rucio" Matte, en estos últimos casos son apodos que provienen desde sus acomodadas infancias razón por la cual no son degradantes, sino más bien "tiernos" y afectivos, que, luego, circulan, se popularizan y masifican desde las redes del colegio generalmente de curas (El Mercurio, 2012).

A nivel histórico, y que han pasado a formar parte de la memoria junto con sus apodos, podemos citar a Pipino, padre de Carlomagno, quien por su baja estatura fue apodado "El Breve". El rey Alfonso X, junto con ser un personaje que siempre aportó económicamente para el desarrollo del arte y ser un músico y poeta, fue reconocido como "El Sabio". El Rey Ricardo de Inglaterra reconocido por su capacidad y arrojo guerrero fue apodado "Corazón de León". Eduardo I de Inglaterra, apodado "El Pataslargas" por sus pies grandes y piernas largas. Ana Isabella de Francia, "La Loba en Celo" debido a que derrocó, junto a su amante, a Eduardo II. Fernando de Aragón e Isabel de Castilla, su mujer, fueron piadosamente llamados "Los Reyes Católicos", 
(se trata más bien de una antisemia) sin que en este caso el apodo alcance a dar cuenta de la poco católica confiscación que hicieron de todas las propiedades de los judíos, al tiempo de expulsarlos en 1492. Luis II de Baviera, personaje excéntrico apodado "El Loco Luis". Vladimir Drácula, príncipe de Valaquia, apodado "El Empalador" por su gusto de sentar en estacas a los invasores turcos; Julio II, Papa entre 1503-1513, apodado "El Terrible", padre de varios hijos; el Papa Juan Pablo II, apodado en su juventud "El Lolek".

\section{LOS APODOS EN EL MUNDO DELICTUAL}

En el caso de los apodos en el mundo delictual, su producción es generada a partir de un clima social que invita a escrutarlo desde sus ambientes no solo lingüísticos, sino también sociológicos y psicológicos entre otros, en los que se construye y configura un modo de percibir al otro, a los demás y al mundo sin necesidad de demostrar su veracidad, en general desde una mirada descalificadora y ofensiva, de alto sentido funcional distintivo y apelativo. También se trata de apodos que son parte clave del proceso de socialización, por ejemplo, en el mundo del narcotráfico es muy probable que algunos de los apodos tengan alcances que denoten ferocidad, algún poder, o surgidos desde la acción: "el capo mexicano Alfredo Beltrán Leyva, apodado "El Mochomo", nombre de una dañina hormiga del noroeste de México" (Periódico Síntesis, 2009). El matón Marco Tulio Moya, apodado "El Baygon" en referencia al insecticida del mismo nombre (ibid.); "El Mataperros", que corresponde a Baltazar Saucedo cuya misión consistía en asesinar a miembros del cartel rival del Golfo. Existen otros que poseen apodos cándidos, por ejemplo, uno de los más feroces asesinos del cartel de la droga en México, Édgar Valdez — apodado por medio de una antisemia - "La Barbie", que por sus ojos azules se le asoció a la esbelta muñeca. En otros casos puede existir más de un apodo con el propósito de hacer más complicada la tarea policial, es más, los testaferros podrían conocer al capo solamente por su apodo desconociendo absolutamente su real identidad.

El apodo en el mundo delictual es funcional, directo y pragmático, al mismo tiempo es constructor de identidad, territorializado desde la propia circunstancia de la realidad delictiva; da cuenta del modo cómo el individuo es percibido por los demás y que va a significar su posicionamiento desde el que se incorpora y moviliza como en los "narcoapodos" antes ejemplificados y que jerarquizan las relaciones, por ejemplo, "El Cuchilla Maldito" o en otros casos de reos más comunes en los que se pueden encontrar apodos más inocentes, como por ejemplo "El Alcalde", en razón de ser el reo que resuelve los problemas a los demás reclusos; "El Golosina", por ser atractivo y deseado por las mujeres. Se trata de nombres que se movilizan en el límite entre lo grosero y lo gracioso como puede ser, por ejemplo, "El car'e ná", aplicado a individuo cuyo rostro no calza con patrón alguno de belleza; "El diario mojado", metáfora para designar a persona confusa a la hora de expresar sus ideas. El apodo también puede serlo de una realidad extrapersonal, como "La villa miseria" que es 
una antisemia con la que el hablante identifica un barrio residencial de hermosas y valiosas casas.

A continuación referiré una selección de apodos recopilados en distintas cárceles del centro sur de Chile, en los que, favorecido entre otras razones por ser recintos cerrados, se observa un despliegue prolífico facilitado desde el habla marginal del reo, las más de las veces aplicados como atribuciones calificativas y cualificantes que, en general, caricaturizan en extremo, por ello el carácter marcadamente hipersémico de los apodos, ridiculizando al individuo a partir de un rasgo negativo, casi con crueldad. En muchos casos se trata de una dimensión y extensión cómica como una antítesis a la dureza de la vida carcelaria.

Se exponen recursividades de referencia a nivel de un corpus de apodos carcelarios, en donde se manifiesta el carácter limítrofe de este tipo de nombres, que van acompañados por el artículo, precisamente porque permite circunscribir la extensión del nombre determinado, al tiempo que el determinante le otorga una fuerza significativa más definitoria. Son, a la vez, nombres altamente conceptualizados, razón por la que corresponden al ámbito de los epónimos.

1. Es frecuente la nominación apodíctica basada en la metaforización de elementos o artefactos provenientes de mundos distintos, por ejemplo "El Microonda", aplicado a persona de baja estatura y que se calienta (excita) rápidamente. Esta deformidad de dos ámbitos semánticos diferentes genera el absurdo que provoca risa, nos permite observar que el apodo puede instituirse desde la intromisión inesperada de un segmento de la realidad, postulándose como enclave antitético de otra más seria como "El Colecta", una metáfora atribuida a persona que permanentemente se le ve parado en las esquinas.

2. El apodo da cuenta de un sentido de realidad que es propio $-\mathrm{y}$ con un grado de verdad - en términos que es exclusivo del portador, por consiguiente, no es un nombre que se pueda "leer" en una esfera de realidad distinta, motivo por el que responde a una atención especial y a una lógica específica. Por ejemplo: "La Baldosa Suelta", disfemismo o antifrasis atribuido a mujer a quien, por lo poco agraciada, nadie quiere fornicar ("pisar" en referencia al apareamiento de las aves).

3. El defecto o la fealdad son referentes de lo burlesco y risible, por lo que se presenta como un ámbito propicio para que el apodo ofensivo encuentre allí residencia, por ejemplo, "El car'e wea" contracción metafórica mediante la que se designa a un sujeto de rostro surcado, arrugado, en analogía con el escroto testicular; en principio, como afirmábamos anteriormente, puede entenderse como una relación basada en la incongruencia de una percepción absurda, que yuxtapone elementos de diferentes dominios de relación, pero que mediante el apodo alcanzan una adecuación de aproximación que le otorga el sentido de vinculación.

4. Un lugar muy importante como referente de los apodos en las cárceles chilenas es el que se ocupa de la sexualidad en términos de promiscuidad, toda vez que se 
trata de apodos en los que prevalece el cuerpo desde un cierto equilibrio precario que se descontrola mediante el apodo, además que favorece las circunstancias de la risa y el sarcasmo, y que aplicado al género femenino es altamente degradante y que desde un punto de vista moral puede ser muy deplorable. Ejemplos:

- "La calcetín", metáfora aplicada a mujer que se entrega fácilmente al acto sexual, "porque siempre se lo ponen".

- "La esmeril", metáfora mediante la cual se designa en el plano real a una mujer que "pasa afilando", es decir, realizando el acto sexual: "del lunfardo 'afilar', y este del it. popular 'filare', galantear (Spotorno, 97).

- "La planch'e sastre", expresión disfémica e hiperbólica mediante la que se refiere a mujer que está en permanente estado de apetencia sexual, sinestésicamente "caliente".

- "La perilla", metáfora que designa a mujer a quien "todos la manosean".

- "La marioneta", hipersemia metafórica mediante la cual se alude a mujer que adopta fácilmente distintas posiciones para realizar el acto sexual.

- "La yegua mansa", expresión metafórica con sentido antisémico referida a mujer que se entrega fácilmente al coito, pues es "fácil de montar".

5. En el mismo plano el apodo puede generar un descontrol del cuerpo debilitado por la risa provocada, en la que el individuo es su cuerpo antes que la posesión de él, puesto que es dominado por la condición física, absolutamente involuntaria, pero ese cuerpo es un vehículo de expresión y condición como un objeto, del modo como nos lo señala Quevedo en el soneto satírico: "Érase un hombre a una nariz pegado", verso perifrástico e hiperbólico para referirse a un hombre narigudo. Otros apodos en situación similar:

- "El pototín" es una antisemia que refiere por medio de la sinécdoque a un individuo de grandes glúteos; no obstante lo anterior, la sufijación arbitraria o deformante le otorga al apodo un valor calosémico de atenuante.

- "El traficante de moco", hipérbole que identifica a sujeto narigudo.

- "La alcachofa", metáfora mediante la cual se nombra a mujer de hermosas nalgas, pero poco agraciada de rostro.

- "El tocadisco" (tornamesa), sinécdoque metafórica que designa a individuo que posee solamente un brazo.

- "La Lucipoto" es un caso de contracción del nombre propio Lucía o Lucila y el americanismo 'poto,' sinécdoque que permite designar a una mujer que al caminar mueve cadenciosamente sus nalgas o culo.

6. Otro referente no menos recurrente a la hora de la construcción de apodos es el que dice relación con la afición por las bebidas alcohólicas, las más de las veces aplicado al ámbito masculino, por ejemplo las siguientes expresiones metafóricas:

- "El suspiro 'e pipa", juego de palabras que permite apodar a individuo que vive permanentemente con hálito alcohólico o estado de embriaguez. 
- "El araña "e parrón", expresión metafórica que refiere a individuo que es bebedor consuetudinario, como si viviera succionando en la parra; ejemplos similares son: "El estropajo "e cantina"; "el arena 'e playa", metáfora que alude a la gran capacidad succionadora del bebedor.

- "El aserrín de ramada", metáfora similar a la anterior que resume expresiones hiperbólicas del beber obstinado.

- "El manguera", metáfora que designa a individuo físicamente muy delgado y bueno para beber, motivo por el que "se moja siempre por dentro".

7. En el contexto de los apodos seleccionados de recintos carcelarios $-\mathrm{y}$ no solo allí- existe un elemento común en este tipo de nombres que es el asociado a la degradación, la ridiculización y cuando no la humillación del individuo, en donde el apodo se utiliza como el prototipo verbal para zaherir, como puede ser la sátira o la ironía, de manera preferente en los ambientes delincuenciales que son, sin duda, más agresivos, de menosprecio, ridiculización y denigratorios. Ejemplos:

- "El cabeza 'e wáter", unidad de significación mediante la que se designa a un individuo de muy precario nivel de pensamiento, que "cuando piensa la caga altiro" ('altiro', modismo chileno para significar 'inmediatamente');

- "El farmacia "e campo", expresión metafórica para nombrar a persona que comete error tras error, por consiguiente, "no tiene remedio", es absolutamente inútil.

- "El fósforo", metáfora para designar a una persona poco ponderada y en exceso impulsiva, en consecuencia, "al primer roce pierde la cabeza".

- "El globo "e palo" apodo metafórico en referencia a individuo de carácter hosco, poco sociable y por tal motivo no es considerado en el vínculo social: "no lo infla nadie".

- "El jote", metáfora que nombra a persona que se hace presente solamente cuando hay asado; "siempre llega cuando hay carne", en referencia al ave carroñera de excelente vista y oportunidad.

- "El hocico 'e wáter", cacosemia mediante la cual se identifica a un sujeto que se caracteriza por su constante mal hálito, en equivalencia al apodo "El suspiro 'e jote", metáfora en referencia al ave que por carroñera se le asocia con el mal aliento.

- "El embudo", metáfora con sentido hipersémico que designa a individuo que por su apetito incontrolable peca de gula, no satisfaciéndose, "llenando", nunca.

- "El calzón de azafata", hiposemia metafórica para designar a individuo que permanece constantemente impávido, "en vuelo", como la mujer que labora a bordo de un avión, pero que en el caso del apodo es consecuencia de los efectos de una droga.

8. Un elemento de base del apodo tiene que ver con el hecho de ser una construcción producto del ingenio, que en los apodos funciona por momentos 
como una diversión, por cuanto desde una mirada horadante escruta, discurre talentosa e inventivamente, ilustrando exageradamente lo ya exagerado, de allí su rasgo hiperbólico, humorístico y lúdico, más allá de la existencia o no de conexiones necesarias con la índole de las personas, cosas u objetos; no obstante, los apodos tienen una capacidad para relacionar aspectos de la realidad previamente inexistentes y en principio incongruentes, chocando por momentos con los límites lingüísticos de lo aceptado. La atención se centra en su concisión y exactitud conceptual, lo que favorece su circulación cumpliendo de este modo una función socializadora de cercanía e, incluso, puede cohesionar el grupo, sobre todo tratándose de circuitos sociales pequeños o cerrados; para los espacios más abiertos, el apodo requiere una explicación de la situación para su real comprensión y efecto de sentido, y en tanto producto de ingenio utiliza la ironía, la paradoja, el absurdo y la ocurrencia. Ejemplos:

- "El nido", metáfora mediante la cual se apoda a una persona que en forma permanente está acomodándose las gónadas, del modo como un ave lo hace en el proceso de empollamiento.

- "El gallina ordenada" es también una metáfora con similar sentido a la anterior, en términos que el individuo vive acomodándose los testículos, como la gallina a sus huevos (vulg. testículos $=$ huevos)

- "El yegua "e teniente", metáfora que identifica al individuo que, a partir de un rasgo somatolálico por un defecto físico en los tendones de Aquiles, camina de manera erguida, levantando ligeramente los pies y perfilándose un tanto de costado, en situación parecida a la que acontece con el animal, especialmente en los desfiles militares.

- "El cazuela 'e jote", hipersemia metafórica mediante la cual se apoda a un sujeto huesudo por su delgadez, de piel morena y "amargo"; sinestesia por medio de la cual el disfemismo vincula con el sabor de la carne del ave carroñera.

- "El cogot'e loza", contracción metafórica que designa a un sujeto que por engreído no presta atención a nadie cuando transita por la calle; no gira el cuello para mirar ni saludar.

- "El parlante 'e canuto", metáfora hiperbólica mediante la que se apoda una persona caracterizada por su locuacidad, en analogía con los predicadores evangélicos, principalmente aquellos que se instalan en espacios públicos con altoparlantes a predicar "la palabra de Dios" en interminables, tediosas y redundantes letanías.

- "El arteriosclerosis", hipersemia metafórica con la que se apoda a un delincuente que asalta de preferencia a personas ancianas, en analogía a que en esa edad puede existir mayor recurrencia de tal lesión arteriosclerótica.

- "El bilingüe" apodo metafórico con el que se designa a persona que "habla español y necedades (chil. "puras huevadas"). 


\section{Bruno Cárdenas Maragaño}

- "El guat'e curanto", este apodo es una contracción que presenta una metáfora referida a la comida típica de Chiloé, la cual se prepara en un hoyo con piedras consistente en un surtido de mariscos, carne de ave, de cerdo, pescado, longaniza, legumbres, es decir, "lleva de todo", por consiguiente, el apodo es aplicado a una persona que por su buen apetito igualmente ingiere de todo.

\section{CONCLUSIONES}

El apodo es el nombre surgido desde una situación de habla, que representa desde una motivación más profunda a una persona a partir de una situación o circunstancia dada, cuya función no es solo es la de identificar, sino, al mismo tiempo, definirla. Se trata, entonces, de un tipo de nombres que cumple una función cognitiva, pues al desenmascarar da cuenta de la realidad personal más allá de aquellas meramente aparenciales.

Los apodos tienen como componente de base el ingenio desde una percepción de comicidad creadora, siendo en muchas ocasiones un estilete que condensa un juicio a modo de sentencia que recae más para mal que para bien sobre el individuo.

Se trata de nombres por medio de los que el individuo es integrado al nombre, ya sea por un rasgo interno o externo. Estos nombres supletorios de comunicación, además, tienen la particularidad de ser de alta satisfacción para los designantes.

La marginalidad, muy principalmente en el caso de los apodos recopilados en los recintos carcelarios - aunque no exclusivamente en aquellos lugaresconstituyen un factor que ayuda a la creación de apodos, sobre todo de humor maligno, toda vez que son muy ofensivos. En general, se trata de nombres que están siempre en zonas fronterizas o marginales, por ello muchas veces son invectivas ridiculizantes de conductas contrarias o contrastantes. Las prohibiciones, injusticias, exclusiones o abusos son catapultadores del ingenio que permite responder a la carencia y en tal caso los apodos son instrumentos de rebelión.

Los apodos recopilados para el presente trabajo van precedidos en general por los artículos, el/la, determinante que es un potenciador de la representación apódica, toda vez que otorgan una fuerza más penetrante a la relación de identidad como prototipo de lo que representan.

No obstante, el apodo es un nombre de recurrencia del habla y que se moviliza en el sistema antes que en la norma de usos, y que es independiente del nivel de habla, donde es posible detectar en ellos una gran riqueza lingüística en su composición, como ha quedado registrado en el presente artículo, en particular la metáfora y el recurso de formas hiperbólicas o hipersémicas, que son a su vez intensificadores de sentido de la burla, del humor, la crueldad o solo para resaltar un aspecto lúdico del designado. Al respecto son también recurrentes los recursos ligados al sentimiento de humor muchas veces lindando con chistes, como la antífrasis o ironía, la hiposemia, la palinsemia, la antisemia, así como la composición y derivación, todas ellas dan paso a 
un festín lingüístico y de jocosidad, en una suerte de contranombres, tanto despectivos como eufemísticos, p.e., un reo llamado Casiano, cuyo apodo es " El Casipoto"; "El Odontólogo", reo cuentero que vive "metiéndoles el dedo en la boca a sus víctimas"; "El Canaleta", pues se baña solo cuando llueve.

En general, el uso de apodos da cuenta denotativa y connotativamente de una pluralidad de interrelaciones, motivaciones y susceptibilidades de clasificación, además de una riqueza lingüística, sociológica y humanista, como acontece con "El caballero de la triste figura". El apodo cumple una interesante función de eficacia semántica en términos de describir, delinear y figurar una persona como parte del proceso de socialización en la comunidad, en general reducida y en la que circulan y que entregan también antecedentes de esas comunidades, tal es el caso de los apodos de empresarios, narcotraficantes, reos y, en general, comunidades pequeñas urbanas o rurales, en unos casos afectivos o lúdicos; en otros, transgresores con carencia total de inocencia.

Es necesario mencionar que el apodo también surge como una exigencia según sea la actividad particularísima que se desempeñe, por ejemplo, en el caso de los espías o agentes de inteligencia cuyas tareas son secretas, en tal caso podría optar por un apodo, o bien, porque el rito religioso o pagano lo exige como en el caso antes ejemplificado de reyes y papas, entre otros.

\author{
Universidad de Los Lagos* \\ Departamento de Humanidades y Artes \\ Av. Fuchslocher 1305, Osorno (Chile) \\ bcardena@ulagos.cl
}

\title{
OBRAS CITADAS
}

Corominas, Joan. Diccionario crítico etimológico, vol I. Madrid: Gredos, 1954.

Colombres, Adolfo. Marco Teórico para el Abordaje y Desarrollo de la Tradición Oral y la Literatura Popular de Nuestra América. Quito: Instituto Andino de Artes Populares (IADAP), 2005.

Chevalier, Maxime. "El Arte de Motejar en la Corte de Carlos V". Cuadernos para la Investigación de la Literatura Hispánica 5 (1981): 61-77.

Real Academia Española. Diccionario de la Lengua Española. XX ${ }^{\mathrm{a}}$ Ed. Madrid: Espasa-Calpe, 1984.

Díez, Germán. Motes y Apodos. Valladolid: Nueva Castilla, 1995.

El Mercurio. Las sabrosas historias detrás de los apodos de los empresarios chilenos. Cuerpo B, Economía y Negocios, 01 de julio de 2012: 2.

Faure, Roberto. Diccionario de nombres propios. Madrid: Espasa, 2002.

Diccionario de apellidos españoles. Madrid: Espasa, 2002.

García Jordán, Juana M. "El Mote o Apodo". Segundas Jornadas sobre el estudio y la enseñanza del léxico. Granada: Método Ediciones, 1995. 
Iglesias, Ángel. "Eponimia: motivación y personificación en el español marginal y hablado". Boletín de la R.A.E. LXI (1981): 297-348.

Moliner, María. Diccionario de uso del español II. Madrid: Gredos, 1981.

Ramírez, Jesús. "Aprovechamiento Educativo y Didáctico de los Apodos del Campo de Cartagena”. Revista Murciana de Antropología 11 (2004): 261-273.

Síntesis. Periódico de Puebla. El Apodo no lo es todo. Puebla, México, 24 de julio de 2009:3.

Spotorno, Radomiro. Glosario Chileno del Amor. Santiago: Planeta, 1995.

Suárez, María Soledad. "Notas al sistema antroponímico asturiano en los siglos X al XII". Asturiensia medievalia 6 (1991): 59-72.

Trapero, Maximiano. "Sobre la capacidad semántica del Nombre Propio". Revista El Museo Canario, Las Palmas de Gran Canaria, LI (1966):337-353. 